\title{
PERANCANGAN GAME FLIGHT SIMULATOR N219 YANG DIKENDALIKAN DENGAN PERANGKAT SMARTPHONE ANDROID MELALUI MEDIA WI-FI
}

\author{
Ariska Hidayat, Bangga Dirgantara Adiputra \\ Program Studi Teknik Informatika \\ Sekolah Tinggi Teknologi Adisutjipto Yogyakarta \\ informatika@stta.ac.id
}

\begin{abstract}
Flight simulation games are generally played on a smartphone or desktop computer. But still there is rarely flight simulation game that combines these two devices simultaneously with each other in a game. Software on a desktop computer that was developed in this research is to fly a plane from take off to landing at controlled by android smartphones using the accelerometer and touch sensors. The aircraft used for flight simulation games are made by PT. Digantara Indonesia, N219. The result of this design is only intended as a study course.
\end{abstract}

Keywords : Flight Simulator, N219, Networking Unity.

\section{Pendahuluan}

Perkembangan penerbangan Indonesia terus maju pesat, yang ditandai dengan telah mampunya bangsa Indonesia memproduksi pesawat terbang sendiri untuk kebutuhan di dalam negeri. Saat ini perusahaan yang memproduksi pesawat terbang di Indonesia adalah PT Dirgantara Indonesia (PT DI). Setelah berhasil mengembangkan pesawat terbang N250 pada tahun 1995, kini PT DI sedang merancang bangun Pesawat terbang ringan N219. Cara untuk menumbuhkan kesadaran dan rasa cinta masyarakat terhadap produk nasional tersebut maka perlu adanya media promosi berupa game services yang bersifat interaktif dan menghibur. Game services yang berhubungan dengan dirgantara adalah sebuah game yang didesain khusus agar pemain seolah-olah sedang menerbangkan pesawat terbang seperti melakukan take off, maneuver, dan landing dengan dibantu oleh berbagai instrument navigator seperti kompas, GPS, dll. Hal ini dapat memberi pengetahuan dan pengalaman lebih dekat kepada masyarakat untuk mengenal pesawat terbang. Sehingga dari pengetahuan yang luas terhadap pesawat terbang tersebut diharapkan masyarakat dapat lebih mencintai produk dalam negeri. Salah satu pesawat yang baru dikembangkan oleh PT. DI adalah pesawat jenis N219.

Penerapan sebuah media game dapat diterapkan dengan menggunakan media desktop atau smartphone. Dua hal tersebut memiliki kekurangan dan kelebihan masing-masing. Beberapa kelebihan yang dimiliki oleh smartphone android adalah terdapatnya sensor seperti sensor touch dan accelerometer. Sensor-sensor tersebut yang dapat digunakan sehingga game lebih interaktif tetapi disisi lain ada kekurangan dari smartphone android yaitu dari kemampuan prosessor terbatas, kualitas grafik rendah dan ukuran layar yang kecil. Oleh karena itulah ada batasan dalam pengembangan game di smartphone android. Sedangkan dengan media desktop yang cenderung memiliki kemampuan prosessor yang tinggi dan kualitas grafik yang bagus ditambah ukuran layar yang besar maka pengambang game dapat melakukan eksplorasi lebih besar dengan kualitas yang baik. Kendala pengembangan game dengan media desktop adalah cara bermain yang hanya mengandalkan mouse dan keyboard sehingga hal tersebut kurang interatif. Walaupun sudah ada alat kemudi game pesawat terbang dengan USB namun harganya lumayan mahal untuk kalangan bawah. Tetapi dengan adanya dukungan (support) wifi pada smartphone android dan desktop maka hal ini dapat dimanfaatkan untuk saling menghubungkan antara kedua media tersebut. Dengan memanfaatkan kelebihan masing-masing 
media tersebut maka dibuat Game Flight Simulator N219 yang dapat dikendalikan dengan Smartphone Android melalui Wifi.

\section{Kajian Pustaka}

Perkembangan flight simulator memiliki prospek yang luar biasa. Banyak peluang untuk digunakan dalam penelitian, hiburan dan edukasi. Flight simulator merupakan simulasi dalam menerbangkan pesawat. Penelitian flight simulator dengan menerbangkan pesawat sudah pernah dibuat, penelitian tersebut pernah diangkat oleh Salam Ariyanto (2014) dengan judul "Simulator Kendali Pesawat Terbang Extra 300 L Berbasis 3D dengan Metode Simulation Game". Pada penelitian tersebut dibuat menggunakan software Adobe Photoshop, 3D Studio Max dan 3DRad. Dalam penelitian tersebut menghasilkan simulasi dengan mengendalikan pesawat jenis Extra $300 \mathrm{~L}$.

Flight simulator pada penelitian Salam belum ada inti game atau tantangan dalam menjalankan simulasi dan belum menerapkan sistem client server yang bisa dimainkan dengan smartphone android sebagai media kendali. Oleh karenanya, pada penelitian Tugas Akhir ini akan membuat game flight simulator yang menerapkan sebuah tantangan sebagai inti game dan juga menerapkan sistem client server.

\section{Metode Penelitian}

\subsection{Pesawat N-219}

Pesawat N-219 merupakan pesawat generasi baru rancangan asli PT DI, yang dikembangkan berdasarkan sertifikat FAR 23/CASR 23 (commuter category). Pesawat berkapasitas 19 tempat duduk ini tidak membutuhkan landasan yang luas, sehingga cocok untuk melayani penerbangan antar daerah dan antar pulau. Di tanah air yang umumnya memiliki landasan pesawat terbang yang tidak panjang.

Sebelum membuat pesawat N-219, sebenarnya PT DI yang berdiri sejak 23 Agustus 1976, telah berhasil membuat berbagai jenis pesawat terbang dan helikopter seperti pesawat NC-212, helikopter NBO-105, helikopter NAS-330 Puma, helikopter NBK-117, helikopter NAS-332 Super Puma, NBell412, pesawat $\mathrm{CN}-235$, dan pesawat n-250 Gatotkaca. Kecuali NC-235 dan N-250, semua pesawat dan helikopter di atas merupakan hasil lisensi dari pihak luar negeri, seperti Spanyol, Jerman dan Prancis.

\subsection{Gerak di Ruang 3 Dimensi}

Posisi benda yang melakukan gerak 3 dimensi dapat dinyatakan dalam 3 vektor satuan yaitu $\mathrm{x}, \mathrm{y}$, dan z. Setiap sumbu setiap object memiliki fungsi masing-masing. Sumbu z mengarah ke kanan object dan sumbu y mengarah atas object dan sumbu z mengarah ke depan object.

\subsection{Diagram Jaringan}

Diagram ini memberi gambaran jaringan yang digunakan supaya antara smartphone Android dan komputer desktop saling terhubung. Dari gambar 1, masing-masing device sudah terhubung dengan access point. Akan tetapi masing-masing device belum saling terhubung. Supaya bisa saling terhubung antara satu dengan yang lain perlu dibuat sistem Client Server. Smartphone sebagai client dan komputer sebagai server. 


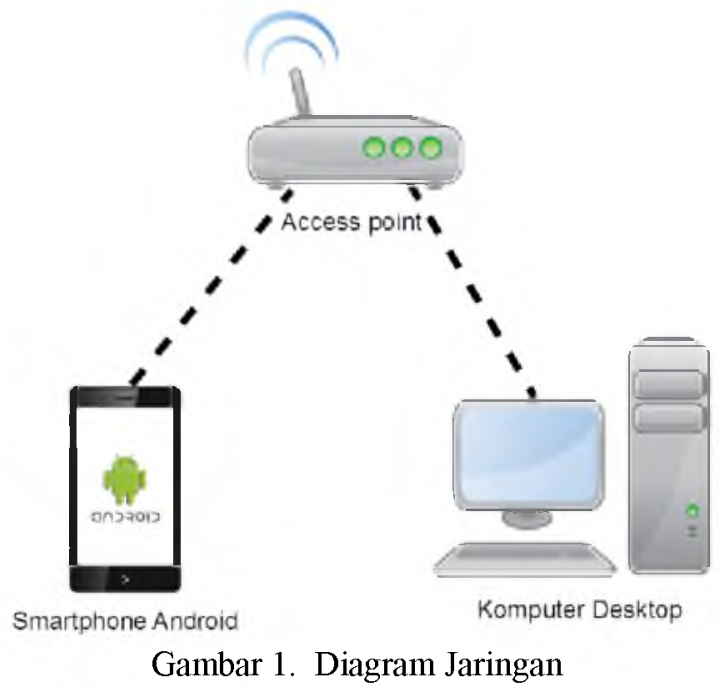

\section{Hasil dan Pembahasan}

\subsection{Pengujian Aplikasi}

Pengujian menggunakan sebuah smartphone android dan sebuah komputer PC yang terhubung dengan media wifi. Gambar 2 merupakan cara menghubungkan antara 2 device tersebut.

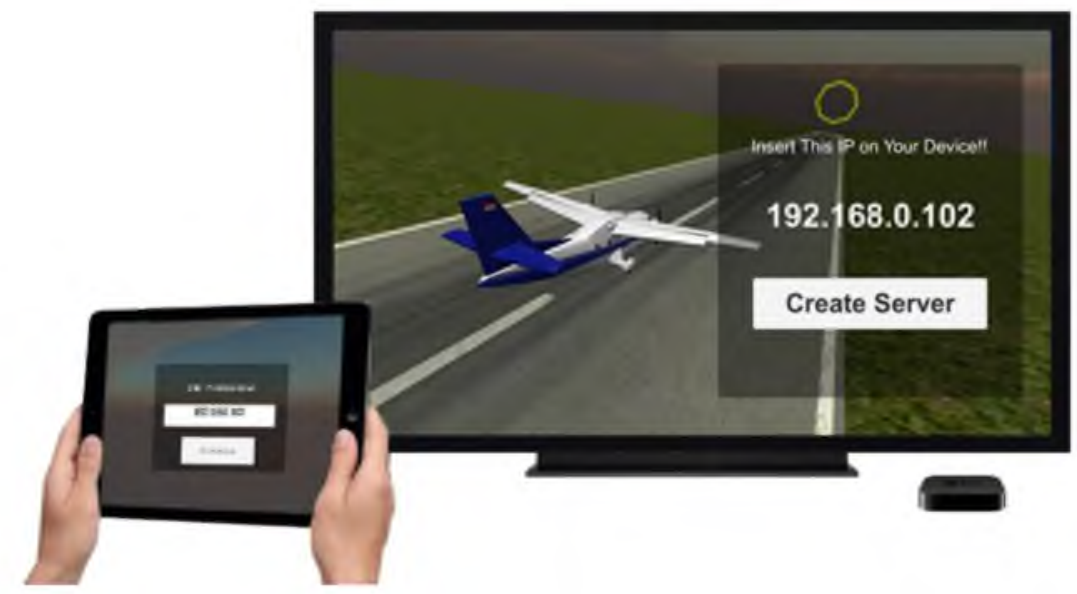

Gambar 2. Menghubungkan Client dengan Server

Setelah melakukan pengujian, Client tidak dapat langsung terhubung dengan server. Diperlukan konfigurasi IP dari sarver di client. Gambar 3 adalah tampilan dasbor ketika masuk gameplay. 


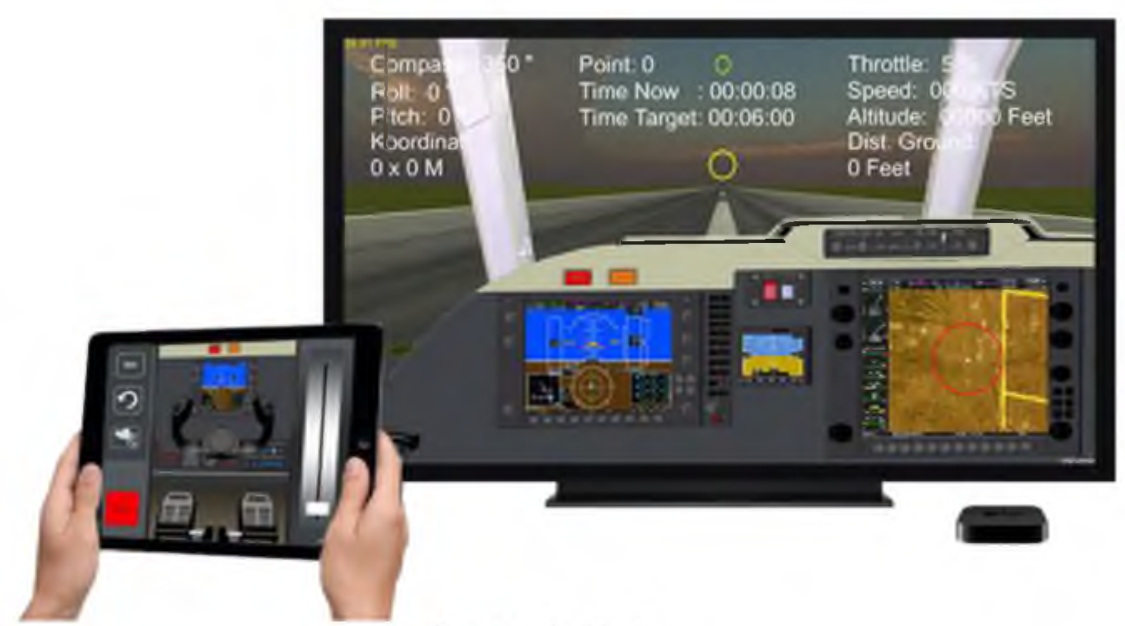

Gambar 3. Dasbor

Dasbor adalah tampilan di dalam ruang kokpit. Di dalam dasbor terdapat instrument-intrument yang dapat membantu pilot dalam mengendalikan pesawat. Intrument-intrument tersebut seperti altimeter, kompas, Speed, altitude dan GPS. Sedangkan Gambar 4 merupakan tampilan gameplay dengan menampilkan pesawat secara utuh.

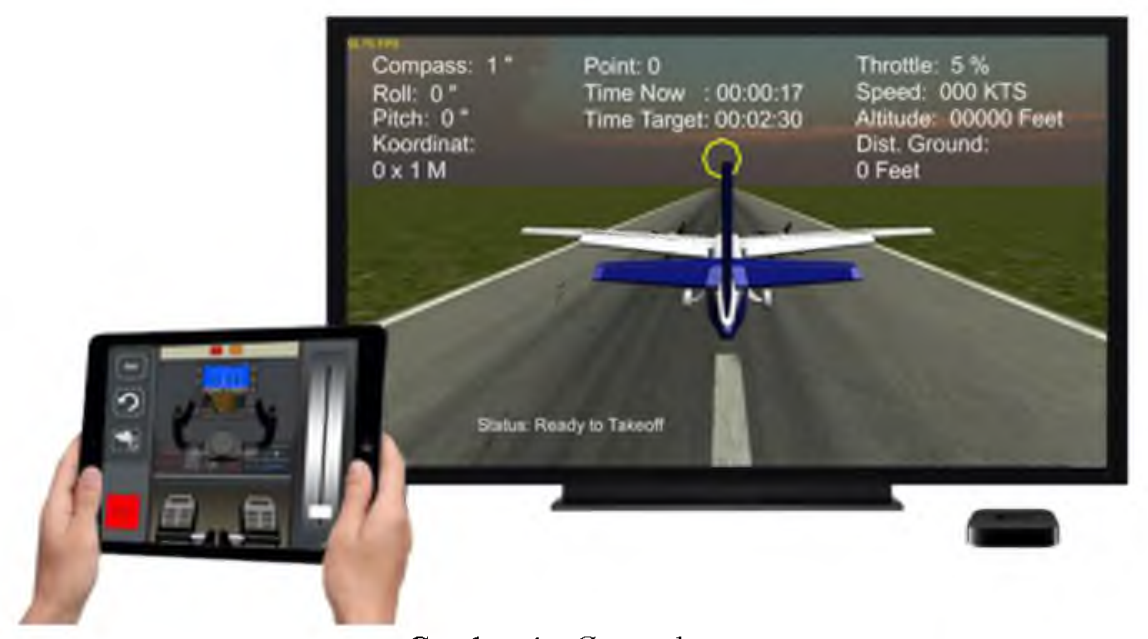

Gambar 4. Gameplay

User mengendalikan pesawat bisa dengan sensor touch. Klik tombol rudder, geser slider Throttle, klik tombol rudder dan untuk kontrol elevator dan aileron cukup dengan memutar-mutar device android secara vertical maupun horizontal. Gambar 5 adalah ketika permainan selesai. 


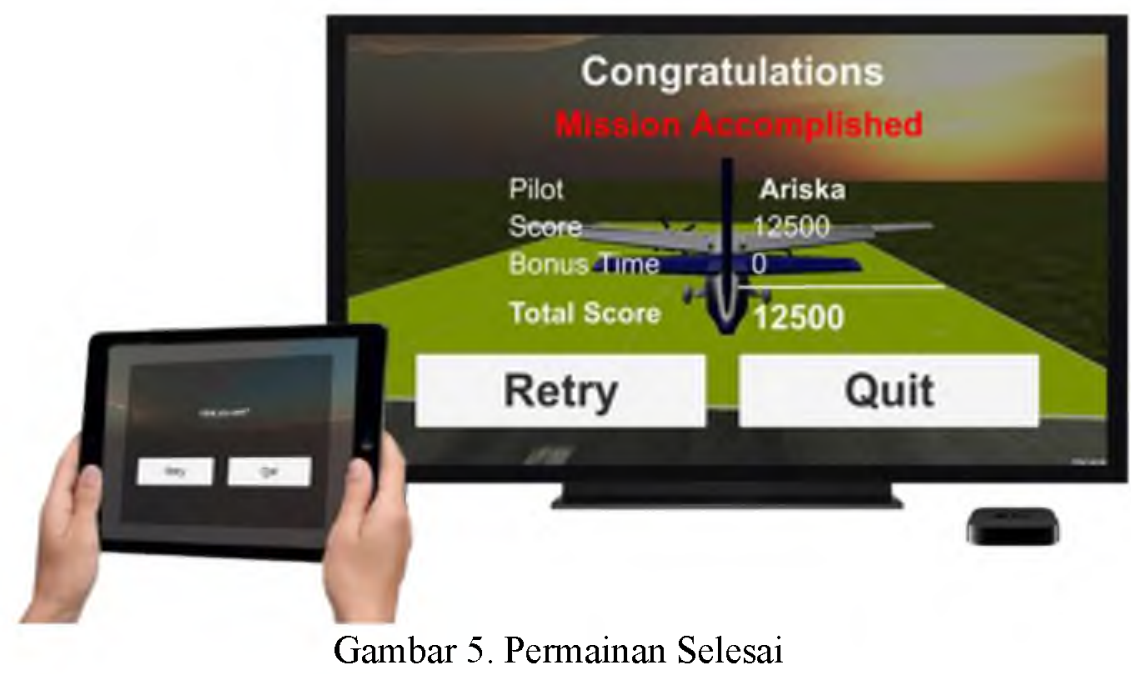

Kondisi akhir permainan bisa karena kehabisan waktu, crash (terjatuh), atau berhasil karena telah menyelesaikan misi.

\subsection{Pembahasan}

Pengujian yang dilakukan adalah menerbangkan pesawat dengan spesifikasi mendekati spesifikasi Pesawat N219. Pesawat bergerak dengan masukkan throttle, brakes, aileron, rudder dan elevator. Pesawat begerak sesuai rute yang telah ditentukan dengan ketinggian penerbangan yang telah ditentukan sesuai dengan jalur terbangnya. Setiap cek point yang dilalui maka user akan mendapatkan 250 point. Point-point tersebut akan diakumulasi ketika permainan selesai. Pada akhir permainan user diharapkan mampu mendaratkan pesawat dan berhenti pada zona kuning. Bila ada sisa waktu maka akan dikalikan 10 sebagai tambahan bonus point.

\section{Penutup}

\subsection{Kesimpulan}

Berdasarkan hasil analisa dari Game Flight Simulator N219 maka dapat disimpulkan:

1. Bermodal smartphone android dapat menghemat biaya pengeluaran untuk membeli alat-alat simulasi pesawat dan pengguna sudah bisa memainkan pesawat dengan mudah.

2. Penggunaan media wifi, Pengguna dapat bisa bermain dengan jarak yang jauh selama media wifi terjangkaui dan tidak direpotkan dengan kabel,

3. Penggunaan data dari PT DI supaya dalam perancangan Game Flight Simulator N219 tidak jauh dari spesifikasi aslinya.

4. Visual game ditampilkan di komputer desktop bertujuan untuk memaksimalkan Kualitas gambar jika dibandingkan dengan di Smartphone Android. Sedangkan pemilihan Smartphone Andorid sebagai media kontrol karena banyaknya fitur-fitur yang dapat dimanfaatkan untuk kenyamanan bermain.

\subsection{Saran} berikut:

Dalam pelaksanaan tugas akhir ini, adapun beberapa saran yang dicantumkan adalah sebagai

1. Game ini monitor navigator pada dasbor pesawat hanya berjalan altimeter dan GPS, untuk kedepannya semua intrument berjalan dengan baik.

2. Game ini untuk menyambungkan koneksi ke server memperlukan input IP, saran pengembang berikutnya dapat mencari otomatis server yang aktif.

3. Pada texture pesawat $\mathrm{N} 219$ hanya menggunakan texture RGB, untuk kedepannya disarankan ditambah texture normal maps supaya hasil lebih bagus. 
4. Game ini memiliki area terbang yang terbatas. Untuk kedepannya diharapkan area terbang tidak terbatas.

\section{Daftar Pustaka}

Allerton, David, 2009, Principles of Flight Simulation, United Kingdom: John Wiley \& Sons, Ltd.

Diston, Dominic J., 2009, Computational Modeling and Simulation of Aircraft and the Enviroment, United Kingdom: John Wiley \& Sons, Ltd.

Zipfel, Peter H., 2007, Modeling and Simulation of Aerospace Vehicle Dynamics Second Edition, Florida: American Institute of Aeronautics and Astronautics, Inc.

Murdaka, Bambang E. J \& Kuntoro, Tri P, 2008, Fisika Dasar untuk Mahasiswa Ilmu-Ilmu Eksakta dan Teknik, Andi Offset.

Fiade, F.M.A., 2011, Socket Pemprograman, Graha Ilmu.

Kusumadewi, Sri, 2003, Artificial Intelligence (Teknik dan Aplikasinya), Graha Ilmu.

Saarlas, Maido, 2007, Aircraft Performance, Canada : John Wiley \& Sons, Inc., Hoboken, New Jersey. 